ИНФОРМАЦИОННОЕ ПРОСТРАНСТВО. МЕДИАСРЕДА INFORMATION SPACE. MEDIA ENVIRONMENT

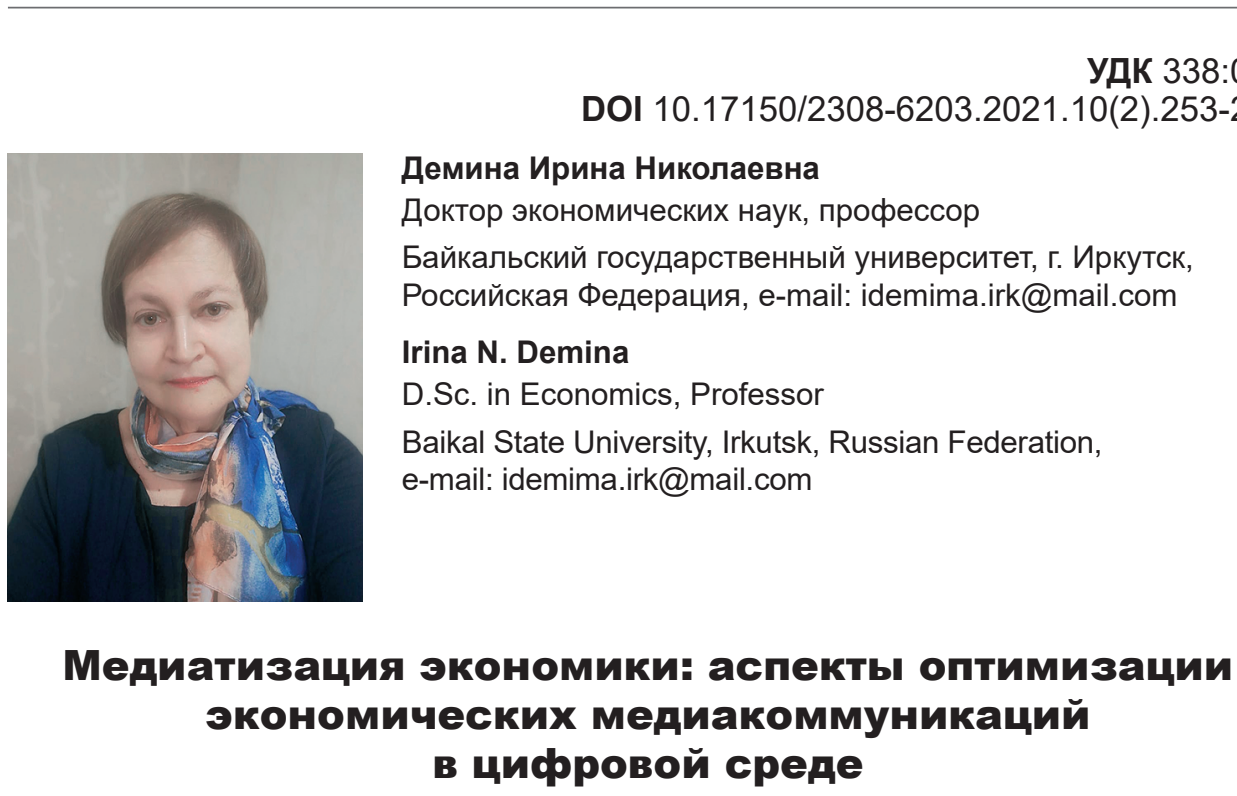

Аннотация. Медиатизация - сравнительно новый подход к пониманию процессов, происходящих в различных сферах жизнедеятельности человека. В медиаисследованиях при обращении к этой теме чаще всего рассматриваются политика, культура, социальные практики, но лишь декларируется и редко исследуется сфера экономики. Цель статьи - определить направления исследований в области медиатизации экономики. В статье рассматриваются традиционные виды экономической массовой коммуникации, определяются их конечные результаты, сделан обзор современных экономических коммуникационных практик (электронная коммерция, социальные сети, шеринговые компании, краудфандинговые платформы, мобильные приложения, блокчейн и криптовалюты), возникших в результате цифровизации экономики. Утверждается, что понятие экономических коммуникаций в цифровом обществе приобретает расширительный характер, а цифровую экономику можно назвать экономикой посредством коммуникаций. В цифровом мире становятся возможными экономические взаимодействия между самими представителями аудитории. Доказывается, что медиатизация - не только процесс, сопровождающий функционирование экономики, но и сами медиа, которые становятся средой бизнеса. Медиатизация экономики порождает новые и актуализирует существующие угрозы для экономического положения аудитории («экономическая власть» монополий, «социальная инженерия», жульничество в сети, введение в заблуждение и пр.). Необходимы правовая база функционирования цифровой экономики, этические кодексы. Интеллектуальный потенциал общества, формируемый в сети, должен развиваться не только в направлении накопления новой экономической информации и технологий ведения сетевого бизнеса, но и обсуждения, выработки и накопления нравственных ограничений, учета аксиологических и деонтологических аспектов. В условиях медиатизации повышается роль экономической журналисти- 
ки, выходящей за рамки исключительно журналистики деловой. Исследование экономических коммуникаций в цифровой среде должно стать одним из актуальных направлений современной теории журналистики.

Ключевые слова. Медиатизация, медиа, экономические массовые коммуникации, медиатизация экономики, медиаисследования.

Информация о статье. Дата поступления 18 апреля 2021 г.; дата принятия к печати 29 апреля 2021 г.; дата онлайн-размещения 7 июня 2021 г.

\title{
Mediatization of the Economy: Aspects of Optimizing Economic Media Communications in the Digital Environment
}

\begin{abstract}
Mediatization is a relatively new approach to understanding the processes that take place in various spheres of human life. In media research, when studying this topic, politics, culture, and social practices are most often examined, but the sphere of economics is only mentioned and has rarely been explored. The purpose of the article is to determine new areas of research in the field of mediatization of the economy. The article examined traditional types of economic mass communication, provided an overview of modern economic communication practices (e-commerce, social networks, co-sharing companies, crowdfunding platforms, mobile applications, block chain and cryptocurrencies) that have arisen as a result of the digitalization of the economy. The author argues that the concept of economic communications in a digital society becomes expansive, and the digital economy can be called an economy via communications. In the digital world, there are economic interactions between the audience members themselves. It is proved that mediatization is not only a process that accompanies the functioning of the economy but the media themselves become a business environment.

The mediatization of the economy triggers new and actualizes the existing threats to the livelihood of the audience ("economic power" of monopolies, "social engineering", scams on the Web, deception, etc.). We need a legal mechanism for regulating the digital economy, ethical codes. The intellectual potential of society created online should develop not only in the direction of the accumulation of new economic information and technologies for running online business, but also in the development of moral rules considering axiological and deontological aspects. In the context of mediatization the role of economic journalism is increasing, going beyond the scope of business journalism. The study of economic communications in the digital environment should become one of the current issues of modern journalism theory.

Keywords. Mediatization, media, economic mass communications, mediatization of the economy, media research.

Article info. Received April 18, 2021; accepted April 29, 2021; available online June 7, 2021.
\end{abstract}

\section{Введение}

Медиатизации как относительно новому парадигмальному подходу в исследованиях коммуникаций посвящено множество теоретических ра- бот и зарубежных, и отечественных авторов. Известно, что само понятие «медиа» происходит от латинского medium - посредник, следовательно, медиатизированные (опосредо- 
ванные) коммуникации и называют «медиа» [1]. В современных условиях, в результате цифровизации медиа перестают быть исключительно посредниками, средствами передачи информации и осуществления коммуникаций. Они выходят за рамки такого узкого подхода и становятся важнейшими акторами глубинных социальных процессов. Согласимся с А.Н. Гуреевой, что «в широком смысле под медиатизацией понимают интеграцию медиа во все социальные сфреры и формирование в обществе единой культурно-коммуникационной системы» [2]. Медиатизация в настоящее время является «ключевой концепций» в изучении медиа. В такой интерпретации медиатизация является с конца XX в. и по сей день предметом изучения зарубежных [3; 4, p. 84; 5, р. 88; 6, p. 48; 7, р. 14-15; 8; 9] и отечественных [10-14] исследователей.

В общем, все современные воззрения на медиатизацию опираются на идею о том, что медиатизированная коммуникация сегодня является базовым способом коммуникации, а сама медиатизация - это процесс (метапроцесс, непрерывный процесс, двойственный процесс), при котором медиа интегрируются в деятельность социальных институтов, одновременно приобретая статус самостоятельных социальных институтов.

Чаще всего, говоря о медиатизации, затрагивают сферу политики, отмечая, что сам термин «медиатизация» начал использоваться в 1980-1990 гг. в контексте воздействия медиа на политическую коммуникацию и политическую деятельность [15; 16]. Отечественные медиаисследователи также часто обращают внимание именно на эту сфреру медиатизации [17; 18]. В то же время не удается отыскать работ, в которых бы обращалось пристальное внимание на медиатизацию не менее важной сферы социальной действительности - экономики, хотя все исследователи согласны, что этот процесс, безусловно, касается и экономической жизни. Возможные подходы к названной области исследований обозначены в данной статье.

\section{Коммуникации и экономика: традиционное прочтение}

Медиатизация, безусловно, теснейшим образом связана с экономикой. Если некоторые исследователи подразумевают под медиатизацией процесс, в результате которого различные элементы общества и культуры (например, работа, досуг, игры и т.д.) принимают форму медиа, перед исследователями должен быть поставлен вопрос, принимает ли форму медиа экономическая система, и, если принимает, в какой степени и в чем это выражается?

Место и значение экономической системы в возникновении, развитии и функционировании средств массовой информации как канала распространения информации и журналистики как деятельности не оспаривается в теории журналистики. Общим местом уже является утверждение, что, в частности, возникновение и быстрое развитие прессы в Западной Европе произошли в огромной степени в результате необходимости удовлетворения назревших потребностей молодого класса буржуазии в информации о событиях на торговых площадках и др. Не будет преувеличением сказать, что развитие капиталистического спо- 
соба производства, национальных, межстрановых, а в дальнейшем мирового рынков, происходило параллельно с развитием информационной системы, и сам способ существования рыночной экономики невозможен без технологий производства, распространения, обмена и потребления информации.

Несмотря на то что сами медиа изначально развивались как сфера бизнеса, были самостоятельными акторами рынка, принимала форму медиабизнеса, нельзя сказать о том, что в то время экономическая система принимает фрорму медиа. Другие экономические сферы производства, финансов, банковской системы, торговли и др. существовали и развивались параллельно и относительно независимо от медиабизнеса. При этом без средств коммуникации, к которым в первую очередь относились медиа, любой бизнес просто не мог бы существовать. Параллельное развитие бизнеса и средств массовой информации породило несколько способов осуществления коммуникаций между акторами формировавшегося с самого начала, а затем сформировавшегося и развивающегося рынка, между ними и конечными потребителями, между бизнесом и государственными институтами. Такими способами всегда являлись реклама, журналистика как таковая, а впоследствии и PR.

Информационный обмен оказывает влияние, иногда даже определяет поведение отдельных личностей, групп людей и социума в целом. Разумеется, информация оказывает влияние и на поведение индивидов на рынке, так называемое «экономическое поведение». Именно этим объясняется неизменная заинтере- сованность бизнеса в средствах распространения информации.

C начала и на протяжении XX в., на наш взгляд, сформировалась довольно устойчивая система экономической массовой информации (ЭМК) на платформе всех известных тогда медиа - печатная пресса, радио, телевидение - и включающая три основных вида ЭМК: реклама [19], PR и экономическая журналистика [20]. В то время акторами рекламы и PR были рекламодатели и корпорации и другие заинтересованные лица, лица, принимающие решения в бизнесе, государственном управлении и т.д.

Главным отличием рекламы и журналистики всегда было декларирование адресата генерирования месседжа: аудитория всегда знала заинтересованное лицо (корпорация, субъекты бизне са, частные лица и др.), в чьих интересах распространяется рекламная информация, - это рекламодатель. Рекламный бизнес стал отдельным бизнесом, регулируемым государственным законодательством, имеющим научную основу, учебную базу, самоорганизацию и т.д. Во всяком случае, аудитория всегда имела возможность четко отделять рекламную информацию от информации журналистской, хотя бы потому что институциональные медиа, т.е. средства массовой информации, зарегистрированные в качестве СМИ, до сих пор обязаны помечать материалы, похожие на редакционные, но оплаченные рекламодателями, значком, указывающим на то, что информация является рекламной («реклама» или «на правах рекламы»).

И реклама, и журналистика оказывают влияние на экономическое 
поведение индивидов, но в этом смысле журналистика всегда противопоставлялась рекламе. Реклама существовала и существует, главным образом, в интересах рекламодателей и рекламопроизводителей, акторами являются именно они. При этом, конечно, потребители меняют свое поведение вследствие рекламного воздействия, во всяком случае, рекламодатели рассчитывают именно на это. Журналистика была относительно самостоятельным институтом, так же, как реклама, регулируемым правовыми актами, основным из которых является Закон о СМИ', внутренними принципами, имеющим собственные функции, миссию, задачи, закономерности и т.д.

PR (Public Relation) и GR (Government Relations) по сути способы взаимодействия корпорации (корпоративный PR) с аудиторией (общественностью) и властными структурами (корпоративный GR), организация коммуникативного пространства корпорации в целях выстраивания собственного имиджа, репутации, воздействия на общественное сознание, формирование повестки дня и т.д. в сознании индивидов или групп людей. Инструменты PR успешно применяются и самими государственными органами (государственный PR) с теми же целями. Очевидно, что PR и GR подчиняются целям актора этой деятельности и служат именно корпоративным структурам. Не существует и, видимо, не может существовать специального законодательства, регламентирующего именно эту дея-

1 О средствах массовой информации : Закон РФ от 27 дек. 1991 г. № 2124-1 : (ред. от 30 дек. 2020, с изм. и доп., вступ. в силу с 01 янв. 2021) // СПС «КонсультантПлюс». тельность. Она подчиняется общим для информационной деятельности законам. Дело в том, что по своим содержательным характеристикам PR и GR чрезвычайно похожи на журналистику. В свою очередь, на протяжении всего существования журналистики продолжаются дискуссии о ее роли и месте в обществе, и большинство авторов, несмотря на частные расхождения, соглашаются, что парадигмально журналистская деятельность направлена, в самом общем виде, на «служение обществу», «человеку с улицы», правдивое представление событий, включая и расследовательскую журналистику, часто или иногда вразрез c PR-материалами. К журналистскому контенту аудитория относилась и до сих пор относится с большим доверием, нежели к PR-материалам, a тем более к рекламе.

Таким образом, журналистика занимает совершенно особое место во взаимоотношениях «власть корпорации - аудитория». Акторы PR и рекламы всегда были заинтересованы в их «мимикрии» под журналистские тексты. Аудитория была относительно защищена от рекламы как фактора изменения экономического поведения тем же законодательством о рекламе. Законов о PR не существует по многим причинам, основными из которых являются существование институционализированных (зарегистрированных в качестве таковых) средств массовой информации в пространстве рынка, медиабизнеса и практически неразличимыми для рядового потребителя характеристиками журналистского и PR-текста.

При этом любые коммуникации, которые можно отнести к экономи- 
ческим (воздействующим на экономическое поведение субъектов рынка - ЭМК, включающие PR, peкламу и экономическую журналистику), занимали прочное положение в рыночной инфраструктуре и играли большую роль в деятельности любой компании (предприятия, фирмы и пр.), будь это деятельность произ- водственная, торговая, финансовая, маркетинговая и пр.

Значение элементов ЭМК в производственной инфраструктуре предприятия во внешней и внутренней среде показано в табл. [21].

Таблица свидетельствует о роли и значении всех видов экономической массовой коммуникации для корпо-

\section{Роль экономической массовой коммуникации в производственной инфраструктуре}

\begin{tabular}{|c|c|c|c|c|}
\hline \multicolumn{2}{|c|}{$\begin{array}{c}\text { Компоненты } \\
\text { системы эконо- } \\
\text { мической мас- } \\
\text { совой коммуни- } \\
\text { кации }\end{array}$} & $\begin{array}{c}\text { Результат } \\
\text { в производствен- } \\
\text { ной инфраструк- } \\
\text { туре (во внешней } \\
\text { среде) } \\
\end{array}$ & $\begin{array}{c}\text { Результат } \\
\text { в производственной } \\
\text { инфрраструктуре (во } \\
\text { внутренней среде) }\end{array}$ & $\begin{array}{c}\text { Конечный результат } \\
\text { в производстве }\end{array}$ \\
\hline \multicolumn{2}{|c|}{ Реклама } & $\begin{array}{l}\text { Создание лояль- } \\
\text { ного потребителя, } \\
\text { рост спроса, моно- } \\
\text { полизация }\end{array}$ & - & $\begin{array}{l}\text { Рост производи- } \\
\text { тельности труда, } \\
\text { уменьшение издер- } \\
\text { жек производства, } \\
\text { рост капитализации } \\
\text { компании-рекламо- } \\
\text { дателя }\end{array}$ \\
\hline \multirow[t]{2}{*}{ PR } & Внешний & $\begin{array}{l}\text { Создание положи- } \\
\text { тельного имиджа } \\
\text { компании, доверия } \\
\text { со стороны потре- } \\
\text { бителей и обще- } \\
\text { ственности }\end{array}$ & - & \multirow{2}{*}{$\begin{array}{l}\text { Рост эффеективности } \\
\text { производства компа- } \\
\text { нии, монополизация } \\
\text { компании-субъекта } \\
\text { деятельности по } \\
\text { связям с обществен- } \\
\text { ностью, «заказчика } \\
\text { PR» }\end{array}$} \\
\hline & Внутренний & - & $\begin{array}{l}\text { Развитие ком- } \\
\text { муникационного } \\
\text { менеджмента, } \\
\text { благоприятного } \\
\text { производственного } \\
\text { климата, форомиро- } \\
\text { вание эффективных } \\
\text { взаимодействий } \\
\text { по управленческой } \\
\text { вертикали и гори- } \\
\text { зонтали }\end{array}$ & \\
\hline \multicolumn{2}{|c|}{ Журналистика } & $\begin{array}{l}\text { Экспертиза } \\
\text { деятельности } \\
\text { производствен- } \\
\text { ных предприятий, } \\
\text { консультации для } \\
\text { инвесторов }\end{array}$ & $\begin{array}{l}\text { Журналистика в } \\
\text { «корпоративных» } \\
\text { СМИ, распростра- } \\
\text { нение актуальной } \\
\text { инфоомации, ком- } \\
\text { муникации между } \\
\text { сотрудниками фрирм }\end{array}$ & $\begin{array}{l}\text { Развитие эффеекти- } \\
\text { ных производств в } \\
\text { противовес субъек- } \\
\text { тивным материалам } \\
\text { PR и рекламы }\end{array}$ \\
\hline
\end{tabular}


рации (заказчика информационной деятельности). Актор (корпорация или другая организация, или государственный орган и др.), как правило, заинтересован и рассматривает свою информационно-коммуникационную политику как субъект-объектные отношения, стремясь корректировать (особенно в рекламной политике) экономическое поведение представителей аудитории. Другой стороной в этих отношениях является широкий круг представителей текущей социальной практики. Именно их интересы должна представлять журналистика, в части экономического поведения - журналистика, которую мы называем экономической.

Такая журналистика парадигмально должна помогать аудитории принимать решения по экономическим вопросам. Тогда основные фрункции экономической журналистики:

1. Комментирование и экспертиза принимаемых акторами решений.

2. Предоставление объективной, релевантной и актуальной информации аудитории в принятии решений в относительно сложных вопросах: какие именно производства будут развиваться в будущем (куда направлять инвестиции), какие предприятия следует считать более эффрективными и современными (следовательно, в какие из них стоит инвестировать), какие финансовые институты являются «прозрачными» и какие фринансовые организации достаточно надежны и пр.

3. Предоставление информации о поведении в повседневной жизни (жизненном мире, повседневности [22]).

Существуют различные методики определения экономической эффективности рекламы как информацион- ной деятельности, корректирующей, например, потребительское поведение аудитории, которые приведены в массе учебников и научных статей (см., например, [23-25]). Практически все они основаны на сравнении финансовых результатов деятельности корпорации вследствие рекламного воздействия с инвестициями в рекламную деятельность. Таким образом в оценке экономической эфффективности прямо связывается рекламное воздействие с экономическим поведением аудитории (повышение спроса на товары и услуги фрирмы, последствиями которого является рост продаж, следовательно, рост доходов и прибыли). Разумеется, реклама сложное явление, и невозможно однозначно трактовать ее воздействие на экономическое поведение индивидов. Методика не так проста, как кажется на первый взгляд: слишком много факторов, которые одновременно с ней воздействуют на экономическое поведение: временной лаг, ценовой фактор, непредвиденные обстоятельства, даже погода. Однако очевидно и прозрачно, что корпорация разрабатывает рекламную политику на результат - максимизацию прибыли.

Воздействие PR на финансовые результаты компании не так очевидны. Из таблицы следует, что ожидаемые эффректы от него имеют нематериальную природу, фирма не может прямо подсчитать экономический эффект от деятельности по связям с общественностью. Компания «Медиалогия» разработала собственную методику оценки компанией эффрективности информационной деятельности: показатель индекса информационного благоприятствования (ИИБ). Этот показатель отражает качество информационного поля ком- 
пании, бренда или персоны, применяется специалистами пресс-служб как один из показателей эффрективности PR и позволяет измерить не только объем публикаций, но и качество упоминаний. Рассчитывается автоматически с применением технологий лингвистического анализа по методике, разработанной компанией «Медиалогия» совместно с учеными-математиками и аналитиками масс-медиа и PR. Значение индекса определяется для каждого объекта (компании, персоны, бренда) в каждом сообщении СМИ, может колебаться от -1000 до +1 000, и чем он больше, тем ярче и позитивнее представлен объект в СМИ. Формула ИИБ включает 3 основных составляющих: индекс цитируемости СМИ (учитывает влиятельность цитирующих ресурсов), позитив/негатив (качественный показатель характера упоминания того или иного объекта в сообщении), заметность сообщения (кумулятивный параметр, учитывающий «рекламный эквивалент» публикации в зависимости от номера полосы, объема сообщения, а также размера аудитории издания) [26].

Этот показатель не является общедоступным на сайте «Медиалогии» ${ }^{2}$. Предполагаю, это дополнительный сервис, рассчитывающийся по заказам компаний, и вряд ли значительно востребован корпорациями, во-первых, в связи с затратами на его расчет, во-вторых, для корпораций он не особо указывает на экономическую эффрективность, прямо не связывая информационную политику с возможностью максимизации прибыли.

2 URL: http://www.mlg.ru/ratings/federal_ smi (дата обращения: 11.04.2021).
Примером применения индекса информационного благоприятствования явилось одно из исследований газеты «РБК daily», компании «Медиология» и Высшей школы экономики, в рамках которого изучалось влияние материалов в прессе за период с 1 июля 2009 г. по 30 июня 2011 г. на капитализацию 48 компаний, акции которых торгуются на ММВБ [27]. Авторы исследования сопоставляли ИИБ и среднюю цену акций компаний. Результаты оказались неоднозначными. Выяснилось, что увеличение индекса на один пункт в среднем влекло за собой рост котировок на $0,073 \%$, хотя у разных компаний данный показатель был разным. Наибольшее влияние ИИБ оказывал на бумаги «Интер РАО», рост которого давал $+17,4$ \% к цене акции компании. Менее всего та или иная информация в СМИ затрагивала «Газпром» и Сбербанк, уменьшение ИИБ которых на 1 пункт не влекло за собой потерь даже тысячной доли рубля в цене акции. В более закрытых компаниях вроде «Сургутнефтегаза» вообще наблюдалась обратная зависимость: даже минимальный рост ИИБ приводил к падению стоимости их акций. В целом, однако, доверие инвесторов к компаниям, выстраивавшим более эффрективный пиар, оказывалось выше.

Возникает закономерный вопрос: зачем же компаниям применять такой дорогостоящий механизм, как PR, если результаты информационной политики компании не влекут за собой роста их капитализации, во всяком случае, это неочевидно. Ответ, видимо, заключается в том, что, во-первых, PR всегда предполагает долговременное функционирование компании на рынке, а это означает 
необходимость сложившегося благоприятного отношения к ней инвесторов, во-вторых, сама методика расчета показателя ИИБ не направлена на исследование отношения рядовых покупателей и потребителей товаров и услуг компаний, особенно на рынках b2c, а возможность максимизации прибыли заключена именно в покупательском поведении потребителей продуктов фрирмы, а не в стоимости акций самой компании для нее и потенциальных инвесторов. Лояльное отношение к компании в долговременном периоде определяет устойчивое положение на рынке, рост или хотя бы стабильность продаж и, как следствие, получение и рост прибыли.

Такая постановка вопроса характерна для экономического взгляда на коммуникативные практики, стратегии и политику любой компании. При этом руководство компании с разной степенью осознанности, возможно, интуитивно, но в настоящее время более осознанно понимает, что прямо и в краткосрочном периоде невозможно связать применение коммуникационного механизма и сбыт, но без разработки информационно-коммуникационной политики и применения ее в практике успешное функционирование компании невозможно. Именно в этом проявляется точка соприкосновения сугубо экономического подхода, предполагающего точный расчет и количественное прогнозирование экономических результатов деятельности фрирмы, и нематериального, качественного воздействия коммуникации между компаниями и потребителями.

На протяжении XX в. стало очевидным, что описанное функционирование системы экономических массовых коммуникаций (реклама, PR и экономическая журналистика) является обязательным условием успешного долговременного существования любой компании, однако, если принять понимание медиатизации как процесс, при котором медиа интегрируются в деятельность компаний (корпораций, фирм и т.д.), еще невозможно было говорить о безусловной медиатизации экономики. Рекламный и PR, медиабизнес были относительно самостоятельными бизнесами, продукт которых, безусловно, оказывал влияние на развитие и существование других бизнесов: производственных, торговых, фринансовых и др., так же, как названные бизнесы развивались, хоть и параллельно с информационными бизнесами, но сохраняли автономность. Современные условия позволили сделать качественный скачок, позволяющий говорить о медиатизации экономики.

\section{Медиатизация экономики в условиях цифровизации}

Основным условием для утверждения тезиса о современной медиатизации экономики стала бурная цифровизация средств массовой информации одновременно с цифровизацией экономики. В 2017 г. в нашей стране была принята программа «Цифровая экономика Российской Федерации», прямо связанная с реализацией Стратегии развития информационного общества в Российской Федерации на 2017-2030 годы ${ }^{3}$, в которой указано,

${ }^{3}$ О Стратегии развития информационного общества в Российской Федерации на 2017-2030 годы : Указ Президента РФ от 9 мая 2017 г. № 203. URL: https://rosstat.gov. ru/storage/mediabank/ukaz_203.pdf (дата обращения: 12.04.2021). 
в частности, что она направлена на создание условий для развития общества знаний в Российской Федерации, повышения степени информированности и цифровой грамотности, а также безопасности как внутри страны, так и за ее пределами ${ }^{4}$.

Цифровая трансформация бизнеса - главный тренд развития не только отечественной, но и мировой экономики. Так, по данным РБК, 68 \% бизнес-лидеров планеты называют цифровую трансформацию главным приоритетом для своих компаний В апреле 2021 г. РБК запустило собственный образовательный цикл «Цифровая трансформация бизнеса», включающий онлайн-лекции профессоров МВА ведущих бизнес-школ мира о том, как выстроить правильную стратегию изменений, а также адаптировать к требованиям времени маркетинг, фринансы и цепочки поставок. На этом примере видно, что медиа активно встраиваются в образовательный процесс, связанный с просвещением представителей бизнеса в области цифровизации экономики. В этом, в частности, проявляется медиатизация экономики.

Медиатизация экономики проявляется в активном использовании информационных возможностей «новых» медиа не только бизнесом, но и рядовыми пользователями интернет-площадок. Об этом, в частно-

${ }^{4}$ Цифровая экономика Российской Федерации : Программа : утв. Распоряжением Правительства РФ от 28 июля 2017 г. № 1632-р. URL: http://static.government.ru/media/files/9gFM 4FHj4PsB79I5v7yLVuPgu4bvR7M0.pdf (дата обращения: 12.04.2021).

5 URL: https://mail.rambler.ru/folder/INBOX/ INBOX_29530/?utm_source=head \&utm campaign=self_promo\&utm_medium $=$ header $\overline{\text { \& }}$ utm_content=mail\&utm_term=inbox (дата обращения: 12.04.2021). сти, говорит глава социальной сети Facebook Марк Цукерберг: «Интернет спасет от нищеты 160 млн чел., от безработицы - 140 млн чел.... если любой сможет продавать продукты через Instagram, общаться и поддерживать клиентов через Messenger и переводить деньги в другую страну через WhatsApp, то это создаст колоссальные возможности во всем мире» [28].

Медиатизация экономики - это не только процесс. В настоящее время основное проявление медиатизации экономики - то, что медиа становятся средой бытования экономики, в которую перемещаются ранее привычные, традиционные схемы функционирования экономической системы. Это сопровождается «ломкой» торговой, финансовой, банковской, сервисной экономики.

Цифровая экономика приобретает новые качественные черты, позволяющие определять ее как «экономику через коммуникации». Составляющие экономической массовой коммуникации (ЭМК) встроены в сетевую экономику особым образом, трансформируются и составляющие ЭМК, и сама экономическая массовая коммуникация становится иной. Сетевая (цифровая) экономика, становясь экономикой через коммуникации, вызывает социальные последствия, поднимает мировоззренческие проблемы, проблемы межпоколенческих взаимодействий, проблемы нравственные, этические, деонтологические. Составляющие сетевой экономики пока обсуждаются больше с технологической стороны, с точки зрения технико-технологических, инструментальных возможностей, но порождают много вопросов в социогуманитарной сфрере [29]. 
Можно сгруппировать наиболее характерные проявления сетевой экономики в следующие группы: электронная коммерция (E-commerce), социальные сети, шеринговые компании, краудфандинговые платформы, мобильные приложения, блокчейн и криптовалюты.

Каждая группа представляет собой особый вид экономических массовых коммуникаций, определенным образом сочетающий традиционные ЭМК. Торговые площадки (маркет-плейсы) - сочетание обычной торговли (с посредником или без, иногда - с так называемыми шоу-румами) с показом с разной степенью подробности предлагаемых товаров, это сочетание торговли с рекламой, демонстрирующее обычные субъект-объектные отношения между институционализированными продавцами и покупателями. В то же время существуют ресурсы, на которых торговля осуществляется между самими потребителями (Avito ${ }^{6}$, «Юла» ${ }^{7}$ и др.), сервисы по продаже недвижимости (Циан ${ }^{8}$ и др.). Основной принцип таких сервисов - доступ к пользованию, а не владению каким-либо благом, а сам сервис соединяет владельцев ресурсов с теми, кто в них нуждается. Коммуникация выходит на новый уровень: такие платформы связывают индивидов, если совпадают потребности участников (продавцов и покупателей, арендодателей и арендаторов). Речь не идет о традиционной, классической рекламе, коммуникации

${ }^{6}$ URL: https://www.avito.ru/irkutsk (дата обращения: 12.04.2021).

7 URL: https://youla.ru (дата обращения: 12.04.2021).

8 URL: https://irkutsk.cian.ru (дата обращения: 12.04.2021). возникают спонтанно и без посредников. Между участниками возникают субъект-субъектные отношения.

В социальных сетях функция форума стала осязаемой, реальной. Здесь очень трудно выделить экономические массовые коммуникации из всего потока информации, и экономическая действительность, экономическая политика государства, экономическое поведение субъектов, включая представителей элиты, бизнеса, самих участников социальной сети становится предметом обсуждения, освещения, оценки. Любая крупная компания уже не может обойтись без представительства в социальных сетях (Facebook, ВКонтакте и др.). Это и непосредственная прямая связь с потенциальными и реальными потребителями, и рекламные мероприятия и материалы, и элементы PR. Компании стараются сохранить субъект-объектные отношения, но сама «идеология», технология социальных сетей не позволяет им это сделать в полной мере в результате широкой обратной связи, интерактивности, обсуждения реального использования товаров и услуг. Рекламодатель должен учитывать это в своей работе. Гораздо эффрективнее, например, работает «сторителлинг», так что умение написания текстов, литературная работа, работа журналиста становится более востребованной, и значение коммуникаций повышается.

Еще одно проявление новой цифровой экономики, «экономики через коммуникации», - шеринговые компании (самоорганизующиеся сервисы для совместного бизнеса). Экономическое понимание такого рода бурно развивающегося бизнеса называют sharing economy 
(от share - делиться) - экономика совместного пользования, «долевая» экономика, экономика сотрудничества и участия. Среди шеринговых сервисов известны арендные сайты, на которых арендовать можно очень многое - от одежды до сложного оборудования (Rentmania - сайт частных объявлений для аренды вещей $\left.{ }^{9}\right),-$ поиск попутчиков для совместных автомобильных путешествий (BеepCar ${ }^{10}$, BlaBlaCar $\left.{ }^{11}\right)$, поиск и бронирование жилья (Tvil.Ru ${ }^{12}$ и др.), совместная аренда помещений для работы (Kovorkingi.ru $\left.{ }^{13}\right)$, аренда автомобилей и др. (каршеринг, самокатшеринг, велошеринг) $)^{14}$. Актуальным становится фудшеринг - перераспределение продуктовых ресурсов.

Речь здесь не идет о классической экономической массовой коммуникации в традиционном понимании (рекламе, PR и журналистике), мы можем говорить о новом типе экономической коммуникации - это непосредственное взаимодействие между участниками рынка, осуществляемое через сеть. Экономический смысл такого рода взаимодействий в том, что они позволяют существенно экономить и получать больший доход от своей собственности. Коммуникации при этом не являются личными,

URL: https://rentmania.com/moskva (дата обращения: 12.04.2021).

10 URL: https://naytipoezdku.ru/beepcarbipkar (дата обращения: 12.04.2021).

11 URL: https://www.blablacar.ru (дата обращения: 12.04.2021).

12 URL: https://tvil.ru (дата обращения: 12.04.2021).

${ }^{13}$ URL: https://www.kovorkingi.ru/kovorking (дата обращения: 12.04.2021).

14 URL: https://zmmt.ru/read/luchshiesheringovye-servisy-v-rossii-3715 (дата обращения: 12.04.2021). но возникает проблема трансакционных издержек ${ }^{15}$, не проработанная еще в достаточной степени законодательством.

Краудфандинг (от англ. crowdfunding) - еще одна составляющая сетевой экономики, коллективный вклад людей, которые используют собственные ресурсы для поддержания проектов, инициированных другими людьми и организациями [29], способ коллективного фринансирования проектов.

Кроме утилитарных, инструментальных задач (сбор средств и получение вознаграждения в будущем), краудфандинговые площадки (самые известные в России: «Планета. ру ${ }^{16}$, «Бумстартер» ${ }^{17}$ ) решают вопроосы коммуникации, сетевого взаимодействия, создания групп пользователей по интересам и потребностям (заняться благотворительной деятельностью, помочь в экологической деятельности, поучаствовать в стартапе интересного бизнес-проекта и т.д.). Результатами такой экономической массовой коммуникации можно назвать установление длительных или кратковременных коммуникативных связей, создание групп по интересам (комьюнити) вокруг нового бизнес-проекта или благотворительной акции и т.д. По существу, краудфандинг - метод социального взаимодействия по поводу инвестирования, рождающийся

15 Трансакционные издержки - затраты, возникающие в связи с заключением контрактов (в том числе с использованием рыночных механизмов); издержки, сопровождающие взаимоотношения экономических агентов.

16 URL: https://planeta.ru (дата обращения: 12.04.2021).

17 URL: https://boomstarter.ru/discover (дата обращения: 12.04.2021). 
на наших глазах пример коллективного разума, самоорганизации групп людей, думающих «в одном направлении» и определяющих успех того или иного экономического начинания и социального проекта. При этом взаимосвязь формируется как между предпринимателем, нуждающимся в финансовых средствах и потенциальными инвесторами (b2p), так и между инвесторами (p2p), а зачастую, сами инвесторы и определяют успех стартапа, неявно участвуя в управлении бизнесом (p2b).

Такого рода экономическая коммуникация, как показывает практика, также может нести угрозы для участников экономического взаимодействия. К ним можно отнести мошенничество, выбор объема инвестирования, высокие издержки управления при принятии решений о дальнейшем развитии бизнеса, конфрликт интересов предпринимателя и инвесторов относительно путей развития бизнеса. Наибольшую опасность представляют вероятность попадания в них проектов мошенников, собирающих средства на несуществующую продукцию, и то, что сами площадки могут создаваться с целью построения финансовых пирамид.

Еще одной формой сетевой экономики посредством коммуникаций являются взаимодействия между субъектами рынка с помощью мобильных приложений, которые становятся широкой средой для ведения бизнеса и одновременно платформой для экономических коммуникаций для рекламных кампаний различных брендов, выхода в смартфоны сайтов организаций, электронной коммерции, взаимодействий внутри организации и с клиентами, социальные сети также повсеместно развиваются главным образом в мобильных устройствах. В мобильных приложениях причудливым образом «стираются» границы между традиционными видами экономических массовых коммуникаций.

Возникновение и существование криптовалют как следующего направления развития сетевой экономики, стало возможным в результате использования блокчейна - особого инструмента для передачи и хранения данных. Возникновение и функционирование технологии блокчейн, казалось бы, не имеет прямого отношения к экономическим коммуникациям, однако, она меняет экономическое поведение аудитории, поэтому также нуждается во внимании медиаисследователей в части медиапотребления и последствий ее использования в повседневной предпринимательской практике.

Технология блокчейн и криптовалюты позволяют сделать вывод о том, что экономические коммуникации в настоящее время выходят за рамки традиционных составляющих маркетингового механизма и экономической журналистики. Экономические сетевые коммуникации становятся самостоятельным механизмом экономики, способным выполнять функции финансовых учреждений, банков, а то и самого государства. Ценность криптовалют основана только на доверии участников цепочки друг к другу, обеспечиваемым существованием криптографрических ключей, которые откроют доступ к тем фрайлам блокчейна, которые предназначаются компьютерам-участникам. Деньги становятся результатом коммуникаций, коллективных действий участников 
процесса. Блокчейн выполняет те же функции, за которые всегда отвечали традиционные фринансовые учреждения, но позволяет это делать без институциональных посредников, что теоретически снижает трансакционные издержки в обществе, но и порождает новые угрозы.

\section{Заключение}

Медиатизация экономики, так же как и других сфер жизни общества, развивается бурными темпами и проявляется в разных формах.

В условиях развития цифровой экономики традиционные экономические массовые коммуникации (рекламa, PR, экономическая журналистика) причудливым образом видоизменяются, границы между ними размываются, а отношения b2c, субъект-объектные отношения между бизнесом и потребителями, аудиторией превращаются в отношения субъект-субъектные, приобретая черты равноправия между участниками информационного процесса. Эти традиционные составляющие в цифровой среде сохраняются, но постоянно приспосабливаются, «затачиваются» под цифровую среду, меняют свои формы, захватывают, пронизывают буквально всю цифровую сфреру бытования коммуникаций. Само понятие экономических коммуникаций приобретает расширительный характер. Цифровую экономику можно даже назвать экономикой посредством коммуникаций.

Кроме того, в результате цифровизации экономические взаимодей- ствия становятся возможными и между всеми представителями текущей социальной практики. Все это проявляется в возникновении новых феноменов (е-commerce, экономика вещей, краудфандинг, технология блокчейна, цифровые деньги...), которые демонстрируют, что медиатизация не только процесс, сопровождающий функционирование экономики, но и самостоятельная среда для бизнеса.

Кроме положительных результатов медиатизация экономики порождает новые и актуализирует существующие угрозы для экономического положения аудитории («экономическая власть» монополий, «социальная инженерия», жульничество в сети, манипуляции и пр.).

Необходима правовая база функционирования цифровой экономики, некие этические кодексы. Интеллектуальный потенциал общества, формируемый в сети, должен развиваться в направлении не только накопления новой экономической информации и технологий ведения сетевого бизнеса, но и обсуждения, выработки и накопления нравственных ограничений, учета аксиологических, деонтологических и других интеллектуальных ресурсов. В этих условиях повышается роль экономической журналистики, которая выходит за рамки исключительно журналистики деловой. Исследование экономических коммуникаций в цифровой среде должно стать одним из актуальных направлений современной теории журналистики.

\section{СПИСОК ИСПОЛЬЗОВАННОЙ ЛИТЕРАТУРЫ}

1. Кирия И.В. История и теория медиа : учебник / И.В. Кирия, А.А. Новикова. - Москва : Высш. шк. экономики, 2017. - 423 с.

2. Гуреева А.Н. Теоретическое понимание медиатизации в условиях цифровой среды / А.Н. Гуреева // Вестник Московского университета. Серия 10: Журналистика. 2016. — № 6. - C. 192-208. 
3. Lundby K. Mediatization: Concepts, Changes, Consequences / K. Lundby. New York : Peter Lang, 2009. - 317 p.

4. Couldry N. The Mediated Construction of Reality / N. Couldry, A. Hepp. - Cambridge : Polity Press, 2018. - 278 p.

5. Schulz W. Reconstructing Mediatization as an Analytical Concept / W. Schulz // European Journal of Communication. - 2004. - Vol. 19, no. 1. - P. 87-101.

6. Hjarvard S. From Bricks to Bytes: The Mediatization of a Global Toy Industry // European Culture and the Media / ed. I. Bondebjerg, P. Golding. — Bristol : Intellect, 2004. P. 43-63.

7. Jansson A. The Mediatization of Consumption: Towards an Analytical Framework of Image Culture / A. Jansson // Journal of Consumer Culture. - 2002. - Vol. 2, no. 1. - P. 5-31.

8. Hjarvard S. The Mediatization of Society. A Theory of the Media as Agents of Social and Cultural Change / S. Hjarvard // Nordicom Review. - 2008. - Vol. 29, no. 2. - P. 105-134.

9. Krotz F. Mediatisierung: Fallstudien zum Wandel von Kommunikation / F. Krotz. Wiesbaden : VS Verlag für Socialwissenschaften, 2007. - $336 \mathrm{~S}$.

10. Вартанова Е.Л. Развивая понимание медиа: от технологий к социальному пространству / Е.Л. Вартанова. - DOI 10.30547/mediaalmanah.5.2020.1224 // МедиаАльманах. - 2020. - № 5 (100). - С. 12-24.

11. Наседкина Н.И. Сущность медиатизации как явления современного общества / Н.И. Наседкина // Universum: Филология и искусствоведение. - 2018. — № 9 (55). C. $15-17$.

12. Шмелева Т.В. Медиатизация как феномен современной культуры и объект исследования / Т.В. Шмелева // Вестник Новгородского государственного университета. 2015. — № 7 (90). - С. 145-148.

13. Ним Е.Г. Исследуя медиатизацию общества: концепт медиатизированных миров / Е.Г. Ним // Социологический журнал. - 2017. - Т. 23, № 3. - С. 8-25.

14. Демина И.Н. Журналистика в мире повседневности: слагаемые конвенциональной целостности как фрактора преодоления конфрликтов / И.Н. Демина, М.В. Шкондин // Вестник Волжского университета им. В.Н. Татищева. — 2021. - Т. 1, № 1 (34). C. $134-143$.

15. Asp K. Mäktiga Mmassmedier: Studier i Politisk Opinionsbildning / K. Asp. — Stockholm : Akademilitteratur, 1986. - $402 \mathrm{~S}$.

16. Mazzoleni G., Schultz W. «Mediatization' of Politics: A Challenge for Democracy?» / G. Mazzoleni, W. Schultz // Political Communication. - 1999. - Vol. 16, no. 3. - P. 247-261.

17. Грибовод Е.Г. Медиатизация политики как институционально-коммуникативный процесс и информационно-стратегический ресурс : дис. ... канд. полит. наук : 23.00.02 I Е.Г. Грибовод. - Екатеринбург, 2017. - 153 с.

18. Федорова Е.В. Медиатизация как важный ресурс современного политического процесса, направленный на адаптацию политических субъектов к новым формам массовых коммуникаций / Е.В. Федорова // Вестник Евразийской науки. - 2018. - Т. 10, № 3.- URL: https://esj.today/PDF/14ECVN318.pdf.

19. Реклама и связи с общественностью: теория и практика / под ред. В.В. Тулупова. - Воронеж : Изд. дом ВГУ, $2015-370$ с.

20. Демина И.Н. Массовая экономическая коммуникация в условиях модернизации общества / И.Н. Демина // Медиаскоп. - 2012. - № 1. - URL: https://www.elibrary.ru/ download/elibrary_17657563_56335885.pdf.

21. Демина И.Н. Экономическая массовая коммуникация в производственной инфрраструктуре / И.Н. Демина // МедиаАльманах. - 2013. - № 1 (54). - С. 26-35.

22. Смирнова О.В. Роль журналистики в медиатизирующемся жизненном мире повседневности / O.B. Смирнова, Л.Г. Свитич, М.Г. Шкондин. - DOI 10.17150/23086203.2020.9(4).595-611 // Вопросы теории и практики журналистики. - 2020. - Т. 9, № 4. - C. 595-611.

23. Корокошко Ю.В. Теоретико методологические подходы к оценке эффрективности комплекса продвижения продукции предприятия / Ю.В. Корокошко // Проблемы теории и практики управления. - 2019. - № 8. - С. 86-100. 
24. Лысова М.Ю. Критерии эфффективности рекламной деятельности / М.Ю. Лысова, Ю.Н. Шамсутдинова // Экономика и управление: новые вызовы и перспективы. 2016. — № 10. - С. 97-99.

25. Исраилов М.К. Проблема оценки эффрективности рекламы / М.К. Исраилов // Аллея науки. - 2020. — Т. 1, № 9 (48). - С. 273-276.

26. Ismailova V. Индекс информационного благоприятствования (ИИБ) / V. Ismailova // Pandia. - URL: https://pandia.ru/text/80/144/13742.php.

27. Дзялошинский И.М. Медиапространство России: коммуникационные стратегии социальных институтов / И.М. Дзялошинский. - Москва : Academia, 2013. - 478 с.

28. Ремизова Р. Что нас ждет в ближайшие десять лет: четыре предсказания МаркаЦукерберга/P. Ремизова//PБК._URL: https://trends.rbc.ru/trends/futurology/5fc68f2d9a 7947408a0ddd6d?utm_source=tw_rbc\&utm_medium=social\&utm_campaign=preview\&utm_ content $=5 \mathrm{fc} 68 \mathrm{f} 2 \mathrm{~d} 9 \mathrm{a} 79 \overline{4} 7408 \mathrm{a} 0 \mathrm{dd} \overline{\mathrm{d}} 6 \mathrm{~d}$.

29. Гусева Д.Е. Краудфандинг: сущность, преимущества и риски / Д.Е. Гусева, Н.И. Малыхин // Современная наука: актуальные проблемы теории и практики. Серия: Экономика и право. - 2014. - № 9-10. - С. 30-34.

\section{REFERENCES}

1. Kiriya I.V., Novikova A.A. Istoriya i teoriya media [History and Theory of Media]. Moscow, HSE Publishing House, 2017. 423 p.

2. Gureeva A.N. Theoretical Understanding of Mediatization in the Digital Environment. Vestnik Moskovskogo universiteta. Seriya 10: Zhurnalistika = Moscow University Journalism Bulletin, 2016, no. 6, pp. 192-208. (In Russian).

3. Lundby K. Mediatization: Concepts, Changes, Consequences. New York, Peter Lang, 2009. 317 p.

4. Couldry N., Hepp A. The Mediated Construction of Reality. Cambridge, Polity Press, 2018. 278 p.

5. Schulz W. Reconstructing Mediatization as an Analytical Concept. European Journal of Communication, 2004, vol. 19, no. 1, pp. 87-101.

6. Hjarvard S. From Bricks to Bytes: The Mediatization of a Global Toy Industry. In Bondebjerg I., Golding P. (eds). European Culture and the Media. Bristol, Intellect, 2004, pp. 43-63.

7. Jansson A. The Mediatization of Consumption: Towards an Analytical Framework of Image Culture. Journal of Consumer Culture, 2002, vol. 2, no. 1, pp. 5-31.

8. Hjarvard S. The Mediatization of Society. A Theory of the Media as Agents of Social and Cultural Change. Nordicom Review, 2008, vol. 29, no. 2, pp. 105-134.

9. Krotz F. Mediatisierung: Fallstudien zum Wandel von Kommunikation. Wiesbaden, VS Verlag für Socialwissenschaften, 2007. $336 \mathrm{~S}$.

10. Vartanova E.L. Developing an Understanding of Media: from Technology to Social Space. MediaAl'manakh = MediaAlmanah Journal, 2020, no. 5 (100), pp. 12-24. DOI: 10.30547/mediaalmanah.5.2020.1224 (In Russian).

11. Nasedkina N.I. An Essence of Mediatization as the Phenomenon of the Modern Society. Universum: Filologiya $i$ iskusstvovedenie = Universum: Philology and Art History, 2018, no. 9 (55), pp. 15-17. (In Russian).

12. Shmeleva T.V. Mediatization as the Phenomenon of Modern Culture and Object of Research. Vestnik Novgorodskogo gosudarstvennogo universiteta = Novgorod State University Bulletin, 2015, no. 7 (90), pp. 145-148. (In Russian).

13. Nim E.G. Exploring Mediatization of Society: The Concept of Mediatized Worlds. Sotsiologicheskii zhurnal = Sociological Journals, 2017, vol. 23, no. 3, pp. 8-25. (In Russian).

14. Demina I.N., Shkondin M.V. Journalism in the World of Everyday Life: Components of Conventional Integrity as a Factor in Overcoming Conflicts. Vestnik Volzhskogo universiteta im. V.N. Tatishcheva = Vestnik of Volzhsky University after V.N. Tatischev, 2021, vol. 1, no. 1 (34), pp. 134-143. (In Russian).

15. Asp K. Mäktiga Mmassmedier: Studier i Politisk Opinionsbildning. Stockholm, Akademilitteratur, 1986. $402 \mathrm{~S}$. 
16. Mazzoleni G., Schultz W. Mediatization of Politics: A Challenge for Democracy? Political Communication, 1999, vol. 16, no. 3, pp. 247-261.

17. Gribovod E.G. Mediatizatsiya politiki kak institutsional'no-kommunikativnyi protsess $i$ informatsionno-strategicheskii resurs. Kand. Diss. Mediatization of politics as an institutional communication process and information and strategic resource. Cand. Diss.]. Ekaterinburg, 2017. 153 p.

18. Fedorova E.V. Mediatization as the Important Resource of Modern Political Process Directed to Adaptation of Political Subjects to New Forms of Mass Communications. Vestnik Evraziiskoi nauki = The Eurasian Scientific Journal, 2018, vol. 10, no. 3. Available at: https:// esj.today/PDF/14ECVN318.pdf (In Russian).

19. Tulupov V.V. (ed.). Reklama i svyazi s obshchestvennost'yu: teoriya i praktika [Advertising and Public Relations: Theory and Practice]. Voronezh State University Publ., 2015. $370 \mathrm{p}$.

20. Demina I.N. Mass Communication in the Economic Conditions of Society Modernization. Mediaskop = Mediascope, 2012, no. 1. Available at: https://www.elibrary.ru/download/ elibrary_17657563_56335885.pdf (In Russian).

21. Demina I.N. Economic Mass Communication in the Industrial Infrastructure. MediaAl'manakh = MediaAlmanah Journal, 2013, no. 1 (54), pp. 26-35. (In Russian).

22. Smirnova O.V., Svitich L.G., Shkondin M.V. The Role of Journalism in Mediatization of the World of Everyday Life. Voprosy teorii $i$ praktiki zhurnalistiki $=$ Theoretical and Practical Issues of Journalism, 2020, vol. 9, no. 4, pp. 595-611. DOI: 10.17150/23086203.2020.9(4).595-611 (In Russian).

23. Korokoshko J.V. Theoretical and Methodological Approaches to Assessment the Effectiveness of the Complex of Promotion Company. Problemy teorii i praktiki upravleniya $=$ Theoretical and Practical Aspects of Management, 2019, no. 8, pp. 86-100. (In Russian).

24. Lysova M.Yu., Shamsutdinova Yu.N. Criteria for the Effectiveness of Advertising Activities. Ekonomika i upravlenie: novye vyzovy i perspektivy = Economics and Management. New Challenges and Perspectives, 2016, no. 10, pp. 97-99. (In Russian).

25. Israilov M.K. The Problem of Assessing the Effectiveness of Advertising. Alleya nau$k i=$ Alley-Science, 2020, vol. 1, no. 9 (48), pp. 273-276. (In Russian).

26. Ismailova V. Information Favored Index. Pandia. Available at: https://pandia.ru/ text/80/144/13742.php (In Russian).

27. Dzyaloshinsky I.M. Mediaprostranstvo Rossii: kommunikatsionnye strategii sotsial'nykh institutov [Russian Media Space: Communication Strategies of Social Institutions]. Moscow, Academia Publ., 2013. 478 p.

28. Remizova R. What awaits us in the next ten years: four predictions by Mark Zuckerberg. RBK. Available at: https://trends.rbc.ru/trends/futurology/5fc68f2d9a7947408a0ddd6d? utm_source=tw_rbc\&utm_medium $=$ social\&utm_campaign=preview\&utm_content $=5 \mathrm{fc} 68 \mathrm{f} 2 \mathrm{~d} 9$ a7947408a0dd̄̄6d (In Russian).

29. Guseva D.E., Malykhin N.I. Crowdfunding: Essence, the Benefits and Risks. Sovremennaya nauka: aktual'nye problemy teorii i praktiki. Seriya: Ekonomika i pravo = Modern Science: actual problems of theory and practice. Series: Law and Economics, 2014, no. 9-10, pp. 30-34. (In Russian).

\section{ДЛЯ ЦИТИРОВАНИЯ}

Демина И.Н. Медиатизация экономики: аспекты оптимизации экономических медиакоммуникаций в цифровой среде / И.Н. Демина. - DOI: 10.17150/23086203.2021.10(2).253-269 // Вопросы теории и практики журналистики. - 2021. - Т. 10, № 2. - C. 253-269.

\section{FOR CITATION}

Demina I.N. Mediatization of the Economy: Aspects of Optimizing Economic Media Communications in the Digital Environment. Voprosy teorii i praktiki zhurnalistiki $=$ Theoretical and Practical Issues of Journalism, 2021, vol. 10, no. 2, pp. 253-269. DOI: 10.17150/23086203.2021.10(2).253-269. 